\title{
Los contornos flexibles del principio del debido proceso en las sanciones disciplinarias*
}

\author{
The Shifting Borders of Due Process in Disciplinary Sanctions
}

\author{
Maria Lourdes Ramirez-Torrado ${ }^{\text {a }}$ \\ Universidad del Norte, Colombia \\ torradom@uninorte.edu.co \\ ORCID: http://orcid.org/0000-0001-6529-0457 \\ Nelson Hernández-Meza \\ Universidad del Norte, Colombia \\ ORCID: http://orcid.org/0000-0003-0872-3177
}

\author{
DOI: https://doi.org/10.11144/Javeriana.vj138.cfpd \\ Redalyc: http://www.redalyc.org/articulo.oa $? \mathrm{id}=82559799009$
}

Fecha de recepción: 16 Junio 2017

Fecha de aprobación: 10 Julio 2018

Fecha de publicación: 30 Mayo 2019

\section{Resumen:}

La inexistencia de un estatuto general disciplinario que determine el contenido y los límites del debido proceso disciplinario, y el hecho de que las normas sectoriales guarden silencio sobre el alcance de este principio han permitido que los órganos de cierre constitucional y contencioso administrativo sean los que resuelvan en cada caso los interrogantes planteados en su aplicación. A todas luces, esta situación genera incertidumbre para el sujeto disciplinado por la ausencia de claridad en torno a esta garantía. Por ello, el objetivo de este documento es determinar y analizar cuál es el alcance que ha tenido este principio en temas disciplinarios, a partir de las sentencias de los tribunales de cierre que han dado forma al postulado en cuestión. Se ha encontrado que, si bien la doctrina jurisprudencial, en principio, es protectora del debido proceso, las garantías que lo rodean tienen, en ocasiones, un alcance discutible, pues a pesar de proteger, sin dudas, un núcleo duro del postulado, en otros aspectos no resultan ser tan garantistas.

Palabras clave: Derecho disciplinario, sanciones administrativas, debido proceso, derecho administrativo sancionador.

\section{Abstract:}

The lack of a general statute in disciplinary matters and the fact that the sectorial rules keep silent on the scope of the principle of due process, has made the high courts, the one to solve the existing gaps. The above causes uncertainty for the individual, on account of the effects of the sanctions. In this framework, the purpose of this article is to determine the scope of the principle of due process in disciplinary matters by analyzing the sentences from the high courts.

Keywords: Disciplinary law, administrative sanctions, due process, administrative sanctioning law.

\section{Introducción}

La suerte que ha tenido el principio del debido proceso no está lejos a la de los otros postulados en el derecho administrativo sancionador, pues su marco teórico - compréndase: concepto, elementos, alcance y excepciones - ha sido resuelto por la doctrina científica y jurisprudencial y no por el legislador. El escenario descrito se replica al estudiar el principio en temas disciplinarios y suscita inquietudes a los distintos actores que intervienen en las actuaciones. Esta situación genera incertidumbre para el sujeto disciplinado, debido a las consecuencias de las sanciones que se pueden imponer. En ciertos casos, estas resultan ser muy onerosas, no solo en dinero, sino también por la imposibilidad de ejercer de forma definitiva, una actividad.

Así pues, el objetivo de este documento es determinar y analizar cuál es el alcance que ha tenido este principio en temas disciplinarios, a partir de las sentencias de los tribunales de cierre que han venido dando forma al principio en cuestión, desde la Constitución de 1991. Entre los hallazgos de esta investigación, se tiene que este principio ha sido analizado recurrentemente tanto por la Corte Constitucional como por el

Notas de autor:

a Autor de correspondencia. Correo electrónico: torradom@uninorte.edu.co 
Consejo de Estado, ya sea como postulado autónomo, o en relación con otros principios; y, quizás, ello en razón a ser una de las máximas que ostentan rango constitucional en materia sancionadora administrativa.

\section{Sujeto y objeto del derecho disciplinario}

El derecho disciplinario es una de las vertientes del derecho administrador ${ }^{1}$ que empodera a la administración, a los jueces, o a los particulares para imponer sanciones que, en términos generales, protegen la correcta marcha de la entidad (pública o privada), o el ejercicio de una profesión. Tiene dos finalidades esenciales, que están estrechamente vinculadas. La primera es la de asegurar el cumplimiento de los deberes del cargo y la segunda, la de "garantizar el cumplimiento de los fines del Estado y de los principios de la función pública" 2 .

Los argumentos empleados principalmente para sustentar la imposición de las sanciones disciplinarias han sido tres. Uno de ellos es el principio de jerarquía ${ }^{3}$ que resulta necesario para complementar la facultad de mando que ostenta la Administración ${ }^{4}$, denominada potestad doméstica ${ }^{5}$. Otro argumento es el relativo a la necesidad de que las actuaciones de esta clase de individuos se realicen dentro de los valores éticos ${ }^{6} \mathrm{y}$ de acuerdo con los principios que regulan la actuación administrativa ${ }^{7}$. Y la hipótesis de la voluntariedad de las relaciones entre las partes ha permitido aplicar el poder disciplinario a aquellas actividades que son indudablemente privadas, pero ejercen potestades administrativas ${ }^{8}$. Aun cuando este argumento deja sin piso otro tipo de relaciones en las que se persigue controlar la disciplina, como ocurre en las cárceles y centros penitenciarios y carcelarios ${ }^{9}$.

En cuanto a los destinatarios de las sanciones administrativas ${ }^{10}$, estas van dirigidas a un número disímil de relaciones que se agrupan tradicionalmente en dos categorías. La primera de ellas comprende a aquellas personas que mantienen una relación laboral de subordinación con la Administración, y también a particulares que cumplen, de modo permanente o transitorio, una función pública, o cumplen labores de interventoría o supervisión en los contratos estatales; y a quienes administren recursos públicos u oficiales 11. No son sujetos de esta manifestación del poder de la Administración "aquellos particulares que presten servicios públicos, salvo que en ejercicio de dichas actividades desempeñen funciones públicas" ${ }^{12}$. Mientras que en el segundo grupo están los particulares que no cumplen funciones públicas, pero debido a sus deberes y obligaciones éticas, se les incluye dentro de la categoría analizada. Este es el caso de los contadores, revisores y auditores o abogados, médicos, psicólogos, o ingenieros, entre otros.

En su artículo 29, la Constitución contempla la potestad sancionadora de la Administración, y los principios que cubren las actuaciones administrativas. Entre los postulados están el debido proceso y los principios de favorabilidad, irretroactividad, legalidad, presunción de inocencia, proceso público, non bis in idem y culpabilidad. Ante la falta de un desarrollo normativo del poder sancionador de la Administración, la Corte Constitucional ha llenado este vacío, al entregar contenido y alcance a cada uno de los principios que regulan esta potestad. En este orden, el debido proceso ha sido una de las máximas a las cuales la Corte Constitucional le ha dedicado mayor atención definiendo su contenido y limitando el poder sancionador de la Administración. Esta noción, lejos de ser simple, y quizás con la intención de proteger al administrado, tiene contornos difusos, que dificultan su conceptualización.

\section{Extensión del debido proceso en asuntos disciplinarios}

Como se expresó, el debido proceso tiene asiento constitucional en el artículo $29^{13}$ de la Constitución y en el bloque de constitucionalidad ${ }^{14}$. Las garantías derivadas del debido proceso en asuntos disciplinarios, vía jurisprudencial $^{15}$, se incorporan a una especie de teoría general del derecho sancionador ${ }^{16}$, que para una 
mejor comprensión se pueden categorizar en tres grandes estancos, a saber: i) garantías del debido proceso previas al inicio de la actuación disciplinaria; ii) garantías de debido proceso que operan durante la actuación disciplinaria; y, iii) garantías del debido proceso aplicables en forma posterior a la imposición de la sanción disciplinaria.

Esta propuesta se toma a partir de las reglas desarrolladas por la jurisprudencia constitucional y contenciosa administrativa. Sin que pueda señalarse como taxativa o excluyente, esta categorización del debido proceso se explica desde la perspectiva del sujeto que puede verse sometido a la potestad sancionadora de la administración.

En la primera categorización sugerida, estimamos que cabrían: la reserva de ley en materia disciplinaria; y la libertad de configuración del legislador. Mientras que el segundo compartimento - esto es, que operan durante el curso de la actuación administrativa disciplinaria - comprende el principio de publicidad de los procesos disciplinarios; la existencia de medidas cautelares en el proceso disciplinario; el derecho a la defensa; la defensa técnica; la coacción y el miedo insuperable; el error como causal de exclusión de la responsabilidad; el principio de favorabilidad; la imparcialidad de la autoridad administrativa que adelante el proceso; la prohibición de las sanciones de plano; el concepto de plazo razonable; y la doble instancia que opera en materia disciplinaria. Finalmente, en la tercera categoría, consideramos garantías como los alcances del control judicial frente a las sanciones disciplinarias; la procedencia de la acción de tutela contra los actos administrativos sancionadores; la limitación temporal del registro de la sanción disciplinaria; y la indemnización en caso de la anulación de las sanciones.

\section{Garantías del debido proceso previas al inicio de la actuación disciplinaria}

\section{Reserva de ley en materia disciplinaria}

La reserva de ley impide que las autoridades administrativas puedan, vía reglamento, determinar faltas, procedimientos, sanciones y las formas para su determinación o la graduación de su sanción, debiendo ser el Congreso quien se ocupe de estos aspectos. Por ello, no son posibles "procedimientos ex post facto, procedimientos ad hoc, ni procedimientos ad personam" ${ }^{17}$. Aunque se ha admitido, por vía de hipótesis, que procedimientos o sanciones disciplinarias puedan ser regulados a través de reglamento del ejecutivo, cuando la ley previamente ha definido los lineamientos básicos para ello, sin que pueda quedar a discrecionalidad de la autoridad administrativa la configuración de la falta, por ejemplo, por quebrar el postulado de tipicidad. Pues el Congreso no puede habilitar en blanco al Ejecutivo ${ }^{18}$ para crear faltas, sanciones o procedimientos ${ }^{19}$, ya que la competencia para limitar garantías como la defensa o etapas procesales recae en el Congreso. De lo contrario, se corre el riesgo de acercarnos a "los estados policivos \#legibus solutus\#, en los que el poder para limitar los derechos está ilimitadamente atribuido a los gobernantes” 20 .

\section{Libertad de configuración del legislador}

Se respeta el debido proceso cuando el legislador, en su libertad de configuración para establecer faltas, sanciones y procedimientos disciplinarios, sean todos estos proporcionales y razonables ${ }^{21}$. Y cuando se pueden matizar los procedimientos disciplinarios, frente al rigor procesal que opera en materia penal ${ }^{22}$.

Frente a la proporcionalidad ${ }^{23}$ y la razonabilidad que debe conservar el legislador se ha entendido ${ }^{24}$ que se viola el debido proceso cuando se crean faltas que equiparan las omisiones, retardos, moras o vencimiento de términos, para resolver actuaciones administrativas o contestar peticiones, con graves violaciones a los derechos humanos. 
De otra parte, en lo correspondiente con la adecuación de los procesos, el Consejo de Estado ha reconocido y entendido como válidas las facultades del legislador para adecuar los procedimientos en materia disciplinaria

${ }^{25}$. Esto le ha permitido al legislador precisar en qué casos y bajo cuáles supuestos es posible mutar del proceso disciplinario escrito al verbal.

\section{Garantías del debido proceso que operan durante la actuación disciplinaria}

\section{El principio de publicidad de los procesos disciplinarios}

La publicidad de los procedimientos tiene dos perspectivas, la interna y la externa. La primera corresponde a las notificaciones y comunicaciones que deben darse a los sujetos procesales o terceros interesados para hacer valer sus garantías sustanciales y procesales. La segunda se concreta en el levantamiento de la reserva de la actuación, una vez formulado el pliego de cargos, a efectos de visibilizar el poder sancionador de la administración frente a la comunidad, y hacer pública la materialización de la correcta conducta oficial. En el evento en que se apertura indagación preliminar, se debe notificar en forma personal a quien es sujeto procesal. Mientras que al quejoso solo se le comunica ${ }^{26}$. Sin embargo, no se viola el debido proceso, como tampoco se genera nulidad de la actuación disciplinaria cuando se obvia la notificación personal al indagado en esta etapa, pero si se demuestra que este, de alguna manera, conoció de la apertura de esta actuación y participó en la práctica de pruebas o las solicitó ${ }^{27}$.

\section{La existencia de medidas cautelares en el proceso disciplinario}

La procedencia de estas medidas dentro del proceso disciplinario encuentra su fundamento en la naturaleza preventiva de este derecho; y proceden cuando sean proporcionales y razonables frente a la gravedad de la conducta, la condición del investigado, y a los hechos investigados. Esta decisión es revisable, luego de surtirse el grado jurisdiccional de consulta ${ }^{28}$, solo por vía de amparo constitucional dado su carácter preparatorio 29. Merece destacar la especial posibilidad que tiene solamente el Procurador General de la Nación que, sin ejercer jurisdicción, puede solicitar a cualquier autoridad administrativa la suspensión de procedimientos administrativos, actos y $\operatorname{contratos}^{30}$. Lo anterior, a partir de un juicio de razón objetivo fundado en dos criterios, así: a) presunta vulneración del ordenamiento jurídico; y, b) presunta defraudación del patrimonio público $^{31}$, que aconsejen la necesidad y urgencia de la solicitud ${ }^{32}$.

\section{Del derecho a la defensa}

Este principio comprende la oportunidad para presentar pruebas, descargos y alegatos en los términos señalados por la ley que contemple el proceso disciplinario de que se trate, sin que pueda concluirse que este derecho sea absoluto, ya que admite relajación, al punto de no admitirse la práctica de pruebas impertinentes 33 .

En cuanto a la libertad probatoria, se ha aceptado, de tiempo atrás ${ }^{34}$, que las copias simples pueden servir de prueba dentro de estas actuaciones, bien sea para imputar y probar la responsabilidad del indagado o para desvirtuarla.

Así mismo, se ha establecido que el hecho de no acoger todos los argumentos defensivos propuestos en sede de la investigación disciplinaria, no genera la nulidad de la sanción ${ }^{35}$. Pero si se niegan pruebas que sean solicitadas para probar la tesis defensiva, se viola el principio de investigar tanto lo favorable como lo 
desfavorable, y en consecuencia con ello, la imparcialidad que se exige del operador disciplinario, y el respeto al debido proceso.

Ahora bien, de conformidad con el CDU, hay libertad probatoria, entre ellas la prueba técnica pericial (peritación), la cual debe ser apreciada de acuerdo con las reglas de la sana crítica ${ }^{36}$. Se requiere un grado de certeza para imputar responsabilidad. Pues de lo contrario, por aplicación del in dubio pro disciplinado, se debe absolver al investigado ${ }^{37}$.

Otro componente del derecho de defensa es el relacionado con el deber del respeto al principio de congruencia que debe existir entre el pliego de cargos que se formule al investigado, y la sanción que se impone. La sanción debe ser la consecuente demostración fáctica de la imputación realizada en el pliego de cargos; sendas piezas procesales deben girar en torno a un mismo eje conceptual fáctico y jurídico ${ }^{38}$.

\section{Defensa técnica}

Al no estar constitucionalmente prescrita, la defensa técnica no es obligatoria en asuntos disciplinarios ${ }^{39}$. El artículo 29 constitucional exige la presencia de un abogado solo en los procesos penales (tanto en sus etapas de investigación como de juzgamiento), dadas la naturaleza del bien jurídico y las sanciones a imponer. En temas disciplinarios, le corresponde al mismo sujeto agenciar sus derechos, y designar o no a un abogado. En este último evento, sus derechos pueden ser representados, con posterioridad al pliego de cargos, por un defensor de oficio o un estudiante de derecho del consultorio jurídico de una universidad legalmente reconocida. De todas formas, no se deben despreciar las consecuencias que para el indagado e investigado puede tener no estar representado por un abogado antes de la formulación del pliego de cargos (en el procedimiento ordinario) o de la citación a audiencia (proceso verbal), pues los hechos probados se constituirán posteriormente en el fundamento de sanciones. Estas últimas podrán revestir la forma de multas cuantiosas o inhabilidades para el ejercicio de un cargo público, incluso, indefinidamente.

\section{La coacción y el miedo insuperable}

En materia disciplinaria, estas figuras son causales de exclusión de responsabilidad, porque, para el derecho disciplinario, la responsabilidad objetiva está proscrita. Este sería el caso, por ejemplo, de quien — bajo la presión de grupos al margen de la ley - realiza actos contrarios a sus deberes funcionales. En este evento, para que se aplique la causal eximente de responsabilidad, como ocurre en materia penal ${ }^{40}$, será necesario acreditar la existencia de una causa ajena al comportamiento del sujeto disciplinable, que hubiese anulado su actuar, mediante cualquier medio, antes, durante o concomitante a la conducta, a través, por ejemplo, de denuncias o informes dirigidos a sus superiores o a las autoridades competentes en que se ponga en evidencia tal situación. Así, los hechos presuntamente ilícitos ${ }^{41}$ se convierten en una conducta irrelevante ${ }^{42}$.

\section{El error como causal de exclusión de la responsabilidad}

Este consiste en el convencimiento pleno del sujeto disciplinable de que su actuación es conforme al ordenamiento jurídico, lo que despoja de ilicitud sus actos al haber una falta de asociación entre su conducta y las consecuencias de su actuar. Así, el error es causal de exclusión de la responsabilidad en materia de derecho sancionador ${ }^{43}$. Sin embargo, el error no puede invocarse, para el caso de los servidores públicos, a partir del desconocimiento de normas legales o reglamentarias que fijan el ámbito de sus deberes funcionales, aun cuando estos no ostenten la calidad de abogado, ya que sus deberes y responsabilidades independientemente de la profesión que ejerzan, se reputan conocidas por ellos ${ }^{44}$. 


\section{Principio de favorabilidad}

La favorabilidad que se reclama en materia disciplinaria hunde sus raíces en los artículos 44 a 47 de la Ley 153 de 1887, englobadas en el derecho fundamental al debido proceso; en el cual la ley posterior se aplicará en tanto sea más favorable, aun cuando no estuviere vigente al momento de la ocurrencia de los hechos investigados ${ }^{45}$; o incluso, la normatividad derogada debe aplicarse en caso de que la norma posterior sea restrictiva o desfavorable al disciplinado ${ }^{46}$.

En este sentido, estimamos que, con arreglo al principio de favorabilidad en cualquier etapa del proceso disciplinario, si la disposición legal o reglamentaria que sirve de fundamento para imputar responsabilidad es derogada, anulada, declarada inexequible o declarada exequible en forma condicionada y se excluye del ordenamiento jurídico la interpretación que sustenta la infracción administrativa, lo procedente es que se archive la actuación. Aun, si ya se presentaron alegatos de conclusión en primera o única instancia; o si se está resolviendo la apelación contra la sanción proferida en primera instancia. E igualmente, debe dejarse sin efectos la sanción disciplinaria, cuando esto ocurre luego de la imposición de la sanción.

Ahora, en los eventos en que haya tránsito de legislación, la favorabilidad puede ser aplicada también en forma atenuada cuando el comportamiento objeto de sanción no desaparezca con la nueva norma, sino que reciba un tratamiento más benigno que en la anterior ${ }^{47}$. Sin que pueda darse aplicación de la lex tertia, dado que para el derecho disciplinario debe existir la misma prohibición que existe en materia penal de utilizar esta figura $^{48}$.

\section{De la imparcialidad de la autoridad administrativa que adelante el proceso}

Esta garantía tiene cabida en el derecho disciplinario, a pesar de su naturaleza inquisitiva, ya que el instructor de la actuación debe ser imparcial ${ }^{49}$. Así, el aspecto medular de la garantía de imparcialidad ${ }^{50}$ se centra en la imposibilidad que tiene el instructor del proceso de realizar, a través del ejercicio de esta función, actuaciones de tipo político o utilizarla como instrumento de presión, en cualquiera de sus formas, pues sería contrario a la "garantía de imparcialidad e independencia reforzada" 51 a la que están obligados los órganos que ejercen el poder disciplinario ${ }^{52}$. Así, no es aceptable que se imponga una sanción disciplinaria que justifica formalmente la violación de un derecho o una disposición legal, y de forma velada, se imponga un castigo de tipo político o se realice un juicio a una política pública ejecutada por el investigado ${ }^{53}$.

La imparcialidad contiene una variable subjetiva y otra, objetiva ${ }^{54}$. La primera hace relación a que los asuntos sometidos al instructor del proceso disciplinario le sean ajenos, "de manera tal que no tenga interés de ninguna clase ni directo, ni indirecto"; y la segunda se refiere a que el instructor no tenga o haya tenido "contacto con el caso sometido a su consideración, desde un punto de vista funcional y orgánico" 55 .

Desde el punto de vista subjetivo, en lo que a la autoridad competente se refiere, esta garantía implica no poder actuar por medio de designios anticipados, prevenciones o recomendaciones ilícitas. Así, habría violación al debido proceso cuando el instructor disciplinario emita, en forma previa, un concepto sobre la responsabilidad de su futuro investigado ${ }^{56}$. Este criterio del Consejo de Estado contrasta con el de la Corte Constitucional, que a su vez sigue al Tribunal de Derechos Humanos Europeo, en cuanto expresa que la imparcialidad "tanto subjetiva como objetiva, en materia disciplinaria no está sujeta a requisitos formales fijos no previstos en la ley”. Pues para advertir su respeto o violación debe analizarse, en cada caso en concreto, "la naturaleza y finalidades del poder disciplinario" 57 ; al punto de que podría sostenerse con fundamento en esa postura, como opera ya en otras latitudes, que para el derecho disciplinario "el hecho de que el juez haya adoptado decisiones antes del juicio, no puede por sí mismo justificar aprensiones en 
cuanto a su imparcialidad" 58 , lo que no parece coherente con las garantías predicadas por la misma doctrina constitucional. Aunque la imparcialidad en materia disciplinaria no exige una separación entre las funciones de investigación, acusación y decisión, lo que es aceptado por la doctrina extranjera solo en caso de "pequeñas causas" 59 .

Otra cuestión que se ha discutido en relación con el principio de imparcialidad en esta materia ${ }^{60}$ es que no es necesario que el cargo de instructor del proceso disciplinario sea de carrera administrativa, para predicar que sea independiente ${ }^{61}$. Pues su actuación puede ser controlada a través de las causales de impedimento y recusación ${ }^{62}$; parece que la responsabilidad de activar el sistema se traslada al disciplinado, en vez de velar por un ordenamiento jurídico que proteja al administrado de decisiones de oportunidad política.

Tampoco se quebranta la imparcialidad del instructor del proceso disciplinario, cuando en el pliego de cargos se utilizan expresiones en las que se califica la conducta, anticipando, al parecer, una decisión sancionatoria ${ }^{63}$, según el Consejo de Estado. Esto parece contrario a todos los planteamientos garantistas que, en ocasiones emite ese tribunal, entre otros, a la presunción de inocencia.

\subsubsection{Prohibición de las sanciones plano}

En materia disciplinaria, como en las demás sub especies del derecho sancionador del estado, están proscritas las sanciones de plano. No siendo posible imponer sanciones sin previa audiencia, sin motivar o cumplir el procedimiento establecido ${ }^{64}$, o sin procedimiento previo a su imposición, pues son contrarias al estado de derecho.

Del mismo modo, no es viable ejecutar una sanción disciplinaria, por ejemplo, sin que se resuelva el recurso de apelación interpuesto por el sancionado en primera instancia, cuando este recurso es admisible ${ }^{65}$. Y, por esta misma vía, tampoco será posible la ejecución de la sanción disciplinaria cuando un recurso esté pendiente de resolver. De hacerse, se estará ante una sanción de plano violatoria del debido proceso.

Ahora bien, en el caso de los disciplinados con fuero sindical su destitución y la inhabilidad general para desempeñar funciones públicas, como sanciones máximas, no operan de plano. Se requieren para su desvinculación efectiva, la presentación de una demanda de levantamiento de fuero sindical y la obtención del permiso para levantarlo, por parte del juez laboral; para ejecutar la sanción de destitución. Todo ello, para garantizar el debido proceso y otros derechos de rango constitucional como el de asociación sindical, libertad sindical y fuero sindical del servidor público ${ }^{66}$.

\section{El concepto de plazo razonable que opera en materia disciplinaria}

Con relación a este tópico, debe señalarse que su aplicación ha sido sostenida de tiempo atrás en el ámbito penal y se reconoce su fundamento a partir del artículo 29 constitucional y de lo previsto en la Convención Americana sobre Derechos Humanos en el artículo 8, como una garantía judicial. Este plazo razonable deberá valorarse a partir de los criterios utilizados por la Corte Interamericana de Derechos Humanos, esto es, considerando: i) la complejidad del asunto; (ii) la actividad procesal del interesado; y (iii) la conducta de las autoridades judiciales ${ }^{67}$. Esta postura ha sido incorporada en nuestro sistema jurídico, por el tribunal constitucional $^{68}$.

Nótese que la garantía señalada hace referencia a su aplicación en sede judicial, al tenor de lo previsto en la Convención Americana de Derechos Humanos ${ }^{69}$. No obstante, esa misma corporación parece extender esta garantía como componente del debido proceso a otros ámbitos de la actividad del Estado, léase la administrativa o jurisdiccional en materia disciplinaria o correctiva ${ }^{70}$. 
Contrario a esta postura, el Consejo de Estado realiza una doble consideración; de una parte, estima que la interpretación convencional del plazo razonable no tiene cabida en materia administrativa sancionadora ${ }^{71}$, en la medida en que se le respete al disciplinado su derecho a la defensa y la contradicción, aunque su desconocimiento genera consecuencias administrativas para el instructor de la actuación. Esto parece poco atinado de cara a las garantías establecidas en estándares internacionales, ya que el ius puniendi del Estado es uno solo y sus garantías se extienden a todas sus manifestaciones.

\section{La doble instancia en las actuaciones disciplinarias}

Esta garantía corresponde al derecho que opera en materia penal de impugnar la sentencia condenatoria que se imponga por primera vez ${ }^{72}$. Aunque si bien en el derecho disciplinario operan las mismas garantías que mutatis mutandi se aplican en materia penal ${ }^{73}$, de forma relajada, de acuerdo con su naturaleza y objeto ${ }^{74}$ ; el derecho a impugnar toda actuación sancionatoria disciplinaria no ha sido reconocido por el sistema de forma clara.

De una parte, en algunos casos se han declarado contrarias a la Constitución normas que anulaban o impedían el derecho a apelar los actos sancionatorios disciplinarios ${ }^{75}$. Pero en otros casos, se ha aceptado la única instancia en procesos administrativos disciplinarios, con dos argumentos: i) se puede acudir ante la jurisdicción de lo contencioso administrativo a cuestionar la legalidad de la sanción ${ }^{76}$; y, ii) es potestad del legislador señalar cuáles son los actos procesales que pueden ser objeto de impugnación ${ }^{77}$.

Esta tensión queda en evidencia cuando se imponen sanciones disciplinarias de carácter jurisdiccional en única instancia ${ }^{78}$ frente a servidores públicos que no tienen fuero constitucional, sin que esto configure una violación de garantías al debido proceso ${ }^{79}$, como ocurre en el caso de los magistrados de tribunal de la Rama Judicial ${ }^{80}$. Esta situación también acontece en el derecho disciplinario administrativo, cuando se revoca el fallo disciplinario absolutorio y se sanciona al investigado en segunda instancia ${ }^{81}$.

\section{Garantías del debido proceso aplicables en forma posterior a la imposición de la sanción administrativa disciplinaria}

\section{Los alcances del control judicial frente a las sanciones disciplinarias}

El espectro del derecho al debido proceso ha sido ampliado, a partir de la aplicación de las normas internacionales, las cuales han permitido construcciones más amplias y garantistas de los derechos, y que son, a su vez, fuentes obligatorias para los jueces de la administración en sus decisiones ${ }^{82}$.

Parece haber empezado un cambio de paradigma en la revisión judicial de los actos administrativos que imponen sanciones de orden disciplinario, a partir de la aplicación de los criterios de razonabilidad y proporcionalidad como mínimos argumentales que deben estar presentes en cualquier actuación que culmine con la imposición de una sanción de orden disciplinario ${ }^{83}$.

Igualmente, otro desarrollo significativo es el relativo a que el control que ejerce la jurisdicción contenciosa administrativa sobre los actos administrativos disciplinarios es pleno e integral, en sede judicial, sin que sea posible reducirlo a un mero juicio de legalidad ${ }^{84}$. En este sentido, a efectos de derruir la presunción de legalidad que amparan las decisiones disciplinarias ${ }^{85}$, se ha sostenido que si la sanción disciplinaria desconoce los principios pro libertatis y pro homine, estos actos deberán ser controlados por el juez de la administración ${ }^{86}$.

Sin embargo, el control pleno e integral de los actos administrativos de carácter disciplinario no lleva a que el control jurisdiccional se convierta en una tercera instancia ${ }^{87}$ pues el juez que controla la legalidad de la 
sanción disciplinaria no posee un poder ilimitado; sino que está restringido a unos estándares convencionales, constitucionales y legales delimitados por la jurisprudencia.

\section{La procedencia de la acción de tutela contra los actos administrativos sancionadores}

Frente a este punto, hay que diferenciar dos casos; el primero es la presentación de acción de tutela contra sanciones disciplinarias impuestas mediante actos administrativos; y el otro es la procedencia de tutelas frente a sanciones de naturaleza jurisdiccional. Para este último caso, la jurisprudencia constitucional ha admitido la acción de tutela ${ }^{88}$ y es indispensable probar la existencia de las causales de procedibilidad generales y específicas del amparo, junto con la existencia de un perjuicio irremediable ${ }^{89}$ que haga necesaria la intervención del juez de tutela; sin que, en ningún caso, pueda considerarse este mecanismo como una instancia judicial adicional para "presentar una interpretación alternativa de la normatividad que el demandante estime acertada" 90 .

En el caso de la procedencia de la tutela para las actuaciones disciplinarias de naturaleza administrativa, es regla judicial que se acrediten las causales genéricas y específicas exigidas para que proceda la tutela contra providencia judicial ${ }^{91}$ y se debe probar que se causa un perjuicio irremediable, porque el control que realizaría la jurisdicción administrativa no sería ineficaz.

Así las cosas, el único elemento diferenciador de la procedencia de tutelas contra actuaciones disciplinarias de orden administrativo o jurisdiccional es que en el primer caso, la situación resulta más exigente; mientras que el interesado debe probar, de forma suficiente, ante el juez constitucional en sede de tutela, la no oportunidad $^{92}$ e ineficacia de la intervención del juez de lo contencioso para evitar la ocurrencia de un perjuicio irremediable en sus derechos fundamentales. La noción determinante para estimar si es o no procedente la acción de tutela contra actuaciones disciplinarias es el concepto de "perjuicio irremediable" 93. Sin embargo, la competencia del juez de tutela en estos casos no se vuelve discrecional, pues tiene como límite de su interpretación los supuestos fácticos del caso concreto, a partir de involucrar en el análisis del mismo "lo establecido en los artículos 6 y 8 del Decreto 2591 de 1991 y la jurisprudencia constitucional, pues la acción de tutela y las acciones ante la jurisdicción de lo contencioso administrativo no son instrumentos que necesariamente se excluyan" ${ }^{94}$.

Lo anterior contrasta con la competencia del juez de la administración de suspender provisionalmente estos actos a través del decreto de medidas cautelares, incluso de urgencia, sin previo traslado a la parte contraria ${ }^{95}$ , y que estas deben ser decididas en el perentorio término establecido para la acción de tutela.

En cuanto a los efectos de la decisión del juez de tutela frente a las actuaciones disciplinarias, estos podrían ser de tres órdenes: a) un amparo en el que se ordena dejar sin efectos una actuación del operador disciplinario y/o se le ordena rehacer el procedimiento adelantado, sin que en estos casos se decrete la terminación de la actuación; b) un amparo transitorio ${ }^{96}$, en el que se ordena al operador disciplinario suspender los efectos de una sanción hasta que el juez de lo contencioso decida el asunto ${ }^{97}$; y, c) un amparo definitivo, en el que se deja sin efecto la actuación disciplinaria ${ }^{98}$.

\section{Limitación temporal del registro de la sanción disciplinaria}

El derecho al olvido se deriva del artículo 15 constitucional ${ }^{99}$. En materia disciplinaria, se determina que en el evento de no existir norma que fije la duración de la sanción disciplinaria en el respectivo registro de antecedentes expedido por la Procuraduría General de la Nación, este podrá contener solamente las sanciones 
ejecutoriadas impuestas dentro de los cinco (5) años anteriores a su expedición ${ }^{100}$. De lo contrario, afectaría el buen nombre y la posibilidad de acceder a un trabajo ${ }^{101}$.

En el caso de los datos consignados en la hoja de vida de los sujetos disciplinables, se pueden registrar las sanciones o actuaciones disciplinarias seguidas contra aquellos, y al ser datos libres de consulta, no está prohibido que circulen ${ }^{102}$; sin que lo anterior permita que se nieguen prestaciones económicas o reconocimientos salariales que por ministerio de la ley se tenga derecho.

\section{La indemnización en caso de la anulación de las sanciones}

Es claro que quien logra obtener pronunciamiento judicial definitivo en el que se declare la invalidez de una sanción, puede reclamar, como consecuencia de ello, el pago de los perjuicios, siempre y cuando consiga probarlos.

En materia disciplinaria, si bien no hay norma expresa que lo ordene, la regla general luego de obtener la nulidad del acto que impone la sanción, es la del pago de los salarios y prestaciones sociales dejados de percibir, en caso de que la sanción hubiere consistido en suspensión temporal del empleo, o el reintegro, en el evento en que la separación del empleo hubiere sido definitiva ${ }^{103}$.

El pago de esas sumas correrá a cargo de la autoridad que impuso la sanción irregular. Así, el pago no correrá por parte de la autoridad nominadora en todos los casos, sino en el evento en que confluyan en la misma autoridad, la calidad de nominador e instructor del proceso sancionador ${ }^{104}$.

De todas formas, no siempre que se anule el acto que impone la sanción de suspensión del empleo o de destitución e inhabilidad podría reclamarse como indemnización el pago de los salarios dejados de percibir o el reintegro, pues bien puede darse el caso de que antes de ejecutarse la sanción, el sancionado renuncie a su empleo, en forma unilateral. En estos casos, no habría, en principio, lugar a este tipo de indemnización; a menos que se probasen perjuicios de otro tipo, para canalizar su pago a partir de la consecuente nulidad de los actos sancionatorios ${ }^{105}$. Son pocos los casos conocidos en los que en sede judicial se han reconocidos perjuicios diferentes a los arriba señalados ${ }^{106}$, esto es, daños morales o el reconocimiento de una pérdida de oportunidad, bien sea porque quienes logran probar la invalidez de las sanciones disciplinarias no lo piden en sus pretensiones de demanda; o porque habiéndolos pedido, no logran probar estos perjuicios ${ }^{107}$. Aunque se ha reconocido el pago de perjuicios "por la pérdida de oportunidad", como consecuencia de la imposición de una sanción de inhabilidad que obligó al disciplinado a renunciar a la ejecución de un contrato estatal; habiéndose declarado luego la nulidad de la sanción ${ }^{108}$.

Esta posición parece ser tímida, pues en ocasiones, por vía de acción de tutela ${ }^{109}$, se dejan sin efecto sanciones disciplinarias de naturaleza jurisdiccional e incluso se ordena el archivo de las actuaciones disciplinarias adelantadas por el Consejo Superior de la Judicatura. Y aunque se acreditan perjuicios de orden moral y económico, nada se dice al respecto.

\section{Conclusiones}

Una vez realizados la revisión y el análisis de la legislación, las posiciones de la doctrina científica y de la Corte Constitucional y el Consejo de Estado que se ocupan del principio del debido proceso en materia disciplinaria, se presentan las siguientes conclusiones:

- El principio del debido proceso en asuntos disciplinarios presenta un desarrollo jurisprudencial, en la medida en que la legislación no se ha encargado de precisar su definición, alcance y consecuencias. Todas las garantías de este principio han sido desarrolladas en cada caso concreto por las autoridades 
administrativas disciplinarias al momento de la imposición de la sanción; el juez contencioso; o, por el juez constitucional al momento de realizar su respectivo control. En todo caso, dejando al disciplinado al vaivén del poder sancionador del Estado.

- El desarrollo que ha tenido el principio en el sector seleccionado muestra que se ha dado cabida a un número disímil de garantías para el administrado y la comunidad, lo que ha ocasionado que sus contornos sean bastantes flexibles, y que su concepto responda más a una lista de garantías extensas, dependiendo del asunto a resolver, que al deseo por conceptualizar el principio. Esto vuelve tortuoso cualquier intento de definir puntualmente el principio. Este es, quizás, su rasgo más sobresaliente.

- Igualmente se destaca que si bien la doctrina jurisprudencial, en principio es protectora del debido proceso, las garantías derivadas de este postulado tienen, en ocasiones, un alcance discutible, pues aun cuando, sin duda, protegen un núcleo duro (entiéndase: legalidad de los procedimientos, publicidad, prohibiciones de sanciones de plano e imparcialidad del juez), otros aspectos del contenido del debido proceso no son tan garantistas. En este último caso, se permite que la misma autoridad en quien confluyen las etapas de investigación y sanción ejerza el derecho disciplinario.

\section{Bibliografía}

\section{Libros}

CALVO-CHARRO, MARÍA, Sanciones medioambientales (Marcial Pons, Madrid, 1999).

FERNÁNDEZ-VIAGAS BARTOLOMÉ, PLÁCIDO, El juez imparcial (Comares, Granada, 1997).

GARBERÍ-LLOBREGAT, JOSÉ, La aplicación de los derechos y garantias constitucionales a la potestad y al procedimiento administrativo sancionador (Trivium, Madrid, 1989).

GARCÍA-GÓMEZ DE MERCADO, FRANCISCO, Sanciones administrativas. Garantías, derechos y recursos del presunto responsable (Comares, Granada, 2007).

GARRIDO-GÓMEZ, MARÍA ISABEL, La función de los jueces: contexto, actividades e instrumentos (Aranzadi, Navarra, 2014).

GONZÁLEZ-GRANDA, PIEDAD, Independencia del juez y control de su actividad (Tirant lo Blanch, Valencia, 1993).

JIMÉNEZ-ASENSIO, RAFAEL, Imparcialidad judicial y derecho al juez imparcial (Cizur Menor, Aranzadi, Navarra, 2002).

MEJÍA-OSSMAN, JAIME, Régimen disciplinario (Ediciones Doctrina y Ley, Bogotá, 2007).

OSSA-ARBELÁEZ, JAIME, Derecho administrativo sancionador. Una aproximación dogmática (Legis, Bogotá, 2000).

PARADA-VÁZQUEZ, RAMÓN, Derecho administrativo II. Organización y empleo público (Marcial Pons, Madrid, 2008).

QUINCHE-RAMÍREZ, MANUEL FERNANDO, El control de convencionalidad (Temis, Bogotá, 2014).

SÁNCHEZ-HERRERA, ESIQUIO MANUEL, Dogmática practicable del derecho disciplinario, preguntasy respuestas (Ediciones Nueva Jurídica, Bogotá, 2007).

SANZ-GANDASEGUI, FRANCISCO, La potestad sancionatoria de la Administración: la Constitución española y el Tribunal Constitucional (Editoriales de Derecho Reunidas, Madrid, 1985).

SOSA-WAGNER, FRANCISCO, La independencia del juez: ¿una fábula? Un relato escrito para personas curiosas y legas (La Esfera de los Libros, Madrid, 2016)

\section{Colaboración en obras colectivas}

AGUILÓ-REGLA, JOSEP, Imparcialidad y aplicación de la ley, en La imparcialidad judicial, 139-166 (CARLOS GÓMEZ-MARTÍNEZ, dir., Consejo General del Poder Judicial, Madrid, 2008). 
HERNÁNDEZ-MEZA, NELSON, Concepto del principio de legalidad en el derecho disciplinario según la doctrina colombiana. Una creación a partir de la doctrina y la jurisprudencia española, en Ensayos sobre derecho disciplinario, 55-102 (Ediciones Nueva Jurídica, Colegio de Abogados en Derecho Disciplinario, Bogotá, 2013).

IBÁÑEZ, PERFECTO ANDRÉS, Imparcialidad judicial e independencia judicial, en La imparcialidad judicial, 41-72 (CARLOS GÓMEZ-MARTÍNEZ, dir., Consejo General del Poder Judicial, Madrid, 2008).

PALMA DEL TESO, ÁNGELES DE, Comentarios al titulo IX de la potestad sancionadora de la ley 30/1992, en Administración Pública y Procedimiento Administrativo: comentarios a la Ley 30/1992, de 26 de noviembre, 467-506 (JOAQUÍN TORNOS-MAS, coord., Bosch, Barcelona, 1994).

\section{Revistas}

CARVAJAL-SÁNCHEZ, BERNARDO, Alcance y limitaciones del debido proceso en el procedimiento administrativo, 4 Revista Digital de Derecho Administrativo, 7-21 (2010). Disponible en: https://revistas.uexternado.edu.co/in dex.php/Deradm/article/view/2765/2449

GALLEGO-ANABITARTE, ALFREDO, Las relaciones especiales de sujeción y el principio de la legalidad de la Administración, 34 Revista de Administración Pública, 11-51 (1961). Disponible en: http://www.cepc.gob.es/Controls/Mav/getData.ashx?MAVqs= aWQ9MjIxNTUmaWRIPTEwMzcmd XJsPTEmbmFtZT0xOTYxXzAzNF8wMTEuUERGJmZpbGU9MTk2MV8wMzRfMDExLlBERiZ0YWJs YT1BcnRpY3VsbyZjb250ZW50PWFwcGxpY2F0aW9uL3BkZg==

GARCÍA-JARAMILLO, LEONARDO, Buenos tiempos para el neoconstitucionalismo (sobre la aparición del examen de proporcionalidad en el derecho constitucional), 120 Vniversitas, 317-332 (2010). Disponible en: https://revist as.javeriana.edu.co/index.php/vnijuri/article/view/14475

GARCÍA-JARAMILLO, LEONARDO, De la "constitucionalización" a la "convencionalización" del ordenamiento jurídico. La contribución del ius constitutionale commune, 36 Revista Derecho del Estado, 131-166 (2016). Disponible en: https://revistas.uexternado.edu.co/index.php/derest/article/view/4576/5264

GARCÍA-LÓPEZ, LUISA FERNANDA, El juez y el precedente: hacia una reinterpretación de la separación depoderes, 128 Vniversitas, 79-120 (2014). Disponible en: https://revistas.javeriana.edu.co/index.php/vnijuri/article/vie $\mathrm{w} / 10131$

GÓMEZ-PAVAJEAU, CARLOS ARTURO, El derecho disciplinario como disciplina jurídica autónoma, 95 Revista Derecho Penal y Criminología, 51-68 (2012). Disponible en: https://revistas.uexternado.edu.co/index.php/der pen/article/view/3420/3107

MICHAVILA-NÚÑEZ, JOSÉ MARÍA, Relación especial de sujeción, en el sector crediticio y estado de derecho, 54 Revista Española de Derecho Administrativo, 243-268 (1987).

MORELL-OCAÑA, LUIS, La lealtad y otros componentes de la ética institucional de la Administración, 114 Revista Española de Derecho Administrativo, 165-194 (2002).

RAMÍREZ-TORRADO, MARÍA LOURDES \& ANÍBAL-BENDEK, HERNANDO V., Sanción administrativa en Colombia, 131 Vniversitas, 107-148 (2015). Disponible en: https://revistas.javeriana.edu.co/index.php/vni juri/issue/view/1005

ROA-SALGUERO, DAVID, La jurisprudencia del Consejo de Estado y sus recientes aportes al derecho disciplinario, 94 Revista Derecho Penal y Criminologia, 97-126 (2012). Disponible en: https://revistas.uexternado.edu.co/index .php/derpen/article/view/3261/2911

SUÁREZ-MANRIQUE, WILSON YESID, La constitucionalización del derecho en el ordenamiento jurídico colombiano, 129 Vniversitas, 317-351 (2014). Disponible en: https://revistas.javeriana.edu.co/index.php/vniju ri/issue/view/853 


\section{Tratados internacionales}

Organización de Estados Americanos, OEA, Convención Americana sobre Derechos Humanos, Pacto de San José, suscrita en San José, Costa Rica, del 7 al 22 de noviembre de 1969. Disponible en: https://www.oas.org/dil/esp /tratados_b-32_convencion_americana_sobre_derechos_humanos.htm

Organización de Naciones Unidas, ONU, Asamblea General, Pacto Internacional de Derechos Civiles y Políticos, adoptado y abierto a la firma, ratificación y adhesión por la Asamblea General en su Resolución 2200 A (XXI), 16 de diciembre de 1966. Disponible en: https://www.ohchr.org/sp/professionalinterest/pages/ccpr.aspx

\section{Normativa colombiana}

Colombia, Constitución Política, 116 Gaceta Constitucional, 20 de julio de 1991. Disponible en: http://www.secreta riasenado.gov.co/senado/basedoc/constitucion_politica_1991.html

Colombia, Decreto 2591 de 1991, por el cual se reglamenta la acción de tutela consagrada en el artículo 86 de la Constitución Política, 40.165 Diario Oficial, 19 de noviembre de 1991. Disponible en: http://www.secretarias enado.gov.co/senado/basedoc/decreto_2591_1991.html

Colombia, Ley 153 de 1887, por la cual se adiciona y reforma los códigos nacionales, la ley 61 de 1886 y la 57 de 1887, 7.151 y 7.152 Diario Oficial, 28 de agosto de 1887. Disponible en: http://www.suin-juriscol.gov.co/viewDocu ment.asp?ruta $=$ Leyes $/ 1792950$

Colombia, Ley 734 de 2002, por la cual se expide el Código Disciplinario Único, CDU, 44.708 Diario Oficial, 13 de febrero de 2002. Disponible en: http://www.secretariasenado.gov.co/senado/basedoc/ley_0734_2002.html

\section{Jurisprudencia internacional}

Corte Interamericana de Derechos Humanos, CorteIDH, Caso Ricardo Canese vs. Paraguay, Serie C-111, Sentencia del 31 de agosto de 2004, fondo, reparaciones y costas. Disponible en: http://www.corteidh.or.cr/docs/casos/ articulos/seriec_111_esp.pdf

Corte Interamericana de Derechos Humanos, CorteIDH, Caso 19 comerciantes vs. Colombia, Serie C-109, Sentencia del 5 de julio de 2004, fondo, reparaciones y costas. Disponible en: http://www.corteidh.or.cr/docs/casos/arti culos/seriec_109_esp.pdf

\section{Jurisprudencia colombiana}

Colombia, Consejo de Estado, Sala de lo Contencioso Administrativo, Sección Primera, Sentencia de 23 de enero de 2014, consejera ponente María Claudia Rojas-Lasso, Radicación 25000-23-24-000-2002-00176-01. Disponible en: http://www.consejodeestado.gov.co/documentos/boletines/147/S1/25000-23-24-000-2002-00176-01.pd $\mathrm{f}$

Colombia, Consejo de Estado, Sala de lo Contencioso Administrativo, Sección Primera, Sentencia de 27 de noviembre de 2015, consejero ponente Roberto Serrato-Valdés, Radicación 6800-1233-3000-2015-00324-01(PI).

Colombia, Consejo de Estado, Sala de lo Contencioso Administrativo, Sección Segunda, Auto de 13 de mayo de 2014, consejero ponente Gerardo Arenas-Monsalve, Radicación 11001-03-25-000-2014-00360-00(1131-14). Disponible en: http://www.consejodeestado.gov.co/documentos/boletines/144/S2/11001-03-25-000-2014-0 0360-00(1131-14).pdf

Colombia, Consejo de Estado, Sala de lo Contencioso Administrativo, Sección Segunda, Sentencia de 2 de agosto de 2012, consejera ponente Martha Teresa Briceño de Valencia, Expediente 2004-00030 (17939).

Colombia, Consejo de Estado, Sala de lo Contencioso Administrativo, Sección Segunda, Subsección A, Sentencia de 19 de agosto de 2010, consejero ponente Alfonso Vargas-Rincón, Radicación 
70001-23-31-000-2000-00132-01(4394-03). Disponible en: http://www.consejodeestado.gov.co/documentos /boletines/PDF/70001-23-31-000-2000-00132-01(4394-03).pdf

Colombia, Consejo de Estado, Sala de lo Contencioso Administrativo, Sección Segunda, Subsección A, Sentencia de 26 de septiembre de 2012, consejero ponente Gustavo Eduardo Gómez-Aranguren, Radicación 11001-03-25-000-2010-00127-00(0977-10). Disponible en: http://www.consejodeestado.gov.co/documentos /boletines/120/S2/11001-03-25-000-2010-00127-00(0977-10).pdf

Colombia, Consejo de Estado, Sala de lo Contencioso Administrativo, Sección Segunda, Subsección A, Sentencia de 2 de mayo de 2013, consejero ponente Alfonso Vargas-Rincón, Radicación 25000232500020040583501 (07312008).

Colombia, Consejo de Estado, Sala de lo Contencioso Administrativo, Sección Segunda, Subsección A, Sentencia de 7 de noviembre de 2013, consejero ponente Gustavo Eduardo Gómez-Aranguren, Radicación 11001-03-25-000-2011-00084-00(0256-11). Disponible en: http://www.consejodeestado.gov.co/documentos /boletines/138/S2/11001-03-25-000-2011-00084-00(0256-11).pdf

Colombia, Consejo de Estado, Sala de lo Contencioso Administrativo, Sección Segunda, Subsección A, Sentencia de 26 de marzo de 2014, consejero ponente Gustavo Eduardo Gómez-Aranguren, Radicación 11001-03-25-000-2013-00117-00(0263-13). Disponible en: https://www.procuraduria.gov.co/relatoria/medi a/file/flas_juridico/710_CE-Rad-0263-13\%20-Sent\%20exalcalde\%20Medellin\%20Alonso\%20Salazar.doc

Colombia, Consejo de Estado, Sala de lo Contencioso Administrativo, Sección Segunda, Subsección A, Sentencia de 12 de mayo de 2014, consejero ponente Alfonso Vargas-Rincón, Radicación 08001-23-31-000-2000-02331-01(0360-09). Disponible en: http://www.consejodeestado.gov.co/documentos /boletines/154/S2/08001-23-31-000-2000-02331-01(0360-09).pdf

Colombia, Consejo de Estado, Sala de lo Contencioso Administrativo, Sección Segunda, Subsección A, Sentencia de 20 de octubre de 2014, consejero ponente Alfonso Vargas-Rincón, Radicación 11001-03-25-000-2012-00172-00(0748-12). Disponible en: https://consejo-estado.vlex.com.co/vid/5606001 66

Colombia, Consejo de Estado, Sala de lo Contencioso Administrativo, Sección Segunda, Subsección A, Sentencia de 19 de febrero de 2015, Consejero ponente Gustavo Eduardo Gómez-Aranguren, Radicación 11001-03-25-000-2011-00606-00 (2319-11). Disponible en: https://www.procuraduria.gov.co/relatoria/med ia/file/flas_juridico/1060_CE-Rad-2319-11.pdf

Colombia, Consejo de Estado, Sala de lo Contencioso Administrativo, Sección Segunda, Subsección A, Sentencia de 23 de septiembre de 2015, consejero ponente Jorge Octavio Ramírez-Ramírez, Radicación 11001-03-25-000-2010-00162-00(1200-10). Disponible en: https://www.procuraduria.gov.co/relatoria/medi a/file/flas_juridico/1237_CE-Rad-1200-10.pdf

Colombia, Consejo de Estado, Sala de lo Contencioso Administrativo, Sección Segunda, Subsección A, Sentencia de 4 de marzo de 2016, consejero ponente Gabriel Valbuena-Hernández, Radicación 11001-03-25-000-2012-00098-00(0438-12). Disponible en: http://www.consejodeestado.gov.co/documentos /boletines/PDF/11001-03-25-000-2012-00098-00(0438-12).pdf

Colombia, Consejo de Estado, Sala de lo Contencioso Administrativo, Sección Segunda, Subsección A, Sentencia de 10 de marzo de 2016, consejero ponente Gabriel Valbuena-Hernández, Radicación 11001-03-25-000-2011-00615-00(2368-11).

Colombia, Consejo de Estado, Sala de lo Contencioso Administrativo, Sección Segunda, Subsección A, Sentencia de 19 de mayo de 2016, consejero ponente Gabriel Valbuena-Hernández, Radicación 11001-03-25-000-2010-00142-00(1064-10). Disponible en: https://www.notinet.com.co/descargar_archivo_ sect.php?numero_no $=480$

Colombia, Consejo de Estado, Sala de lo Contencioso Administrativo, Sección Segunda, Sentencia de 11 de julio de 2013, consejero ponente Gustavo Gómez-Aranguren, Radicación 2011-0122.

Colombia, Consejo de Estado, Sala de lo Contencioso Administrativo, Sección Segunda, Subsección B, Sentencia de 11 de julio de 2013, consejero ponente Gerardo Arenas-Monsalve, Radicación 
52001-23-31-000-2004-00188-02(1982-09). Disponible en: http://www.consejodeestado.gov.co/documentos /boletines/128/S2/52001-23-31-000-2004-00188-02(1982-09).pdf

Colombia, Consejo de Estado, Sala de lo Contencioso Administrativo, Sección Segunda, Subsección B, Sentencia de 27 de febrero de 2014, consejera ponente Bertha Lucía Ramírez de Páez (E), Radicación 11001-03-25-000-2012-00888-00(2728-12). Disponible en: http://www.consejodeestado.gov.co/documentos /boletines/147/S2/11001-03-25-000-2012-00888-00(2728-12).pdf

Colombia, Consejo de Estado, Sala de lo Contencioso Administrativo, Sección Segunda, Subsección B, Sentencia de 27 de noviembre de 2014, consejera ponente Sandra Lisset Ibarra-Vélez, Radicación 11001-03-25-000-2010-00196-00 (1486-10).

Colombia, Consejo de Estado, Sala de lo Contencioso Administrativo, Sección Segunda, Subsección B, Sentencia de 16 de marzo de 2015, consejero ponente Sandra Lisset Ibarra-Vélez, Radicación 11001-03-25-000-2011-00326-00(1233-11). Disponible en: http://relatoria.consejodeestado.gov.co/Docume $\mathrm{nt} /$ ?docid=11001-03-25-000-2011-00326-00(1233-11)

Colombia, Consejo de Estado, Sala de lo Contencioso Administrativo, Sección Segunda, Subsección B, Sentencia de 16 de abril de 2015, consejera ponente Sandra Lisset Ibarra-Vélez, Radicación 11001-03-25-000-2012-00352-00(1353-12). Disponible en: https://www.alcaldiabogota.gov.co/sisjur/norma s/Norma1.jsp?i=63043

Colombia, Consejo de Estado, Sala de lo Contencioso Administrativo, Sección Segunda, Subsección B, Sentencia de 30 de julio de 2015, consejera ponente Sandra Lisset Ibarra-Vélez, Radicación 11001-03-25-000-2010-00142-00 (0609-2012).

Colombia, Consejo de Estado, Sala de lo Contencioso Administrativo, Sección Segunda, Subsección B, Sentencia de 4 de febrero de 2016, consejera ponente Sandra Lisset Ibarra-Vélez, Radicación 11001-03-25-000-2012-00146-00(0627-12). Disponible en: https://guiapgn.info/pgn/v2/gd/docs/11001-03 -25-000-2012-00146-00(0627-12).html

Colombia, Consejo de Estado, Sala de lo Contencioso Administrativo, Sección Segunda, Subsección B, Sentencia de 4 de febrero de 2016, consejera ponente Sandra Lisset Ibarra-Vélez, Radicación 11001-032-5000-2013-01790-00 (4752-13). Disponible en: https://consejo-estado.vlex.com.co/vid/649772469

Colombia, Consejo de Estado, Sala de lo Contencioso Administrativo, Sección Segunda, Subsección B, Sentencia de 18 de febrero de 2016, consejera ponente Sandra Lisset Ibarra-Vélez, Radicación 810012333000201400025-01(1582-2015).

Colombia, Consejo de Estado, Sala de Servicio y Consulta Civil, Concepto de 30 de octubre de 2013, consejero ponente William Zambrano-Cetina, Radicación: 2163. Numero Único: 11001030600020130040000.

Colombia, Consejo de Estado, Sección Tercera, Sentencia de 20 de noviembre de 2008, consejera ponente Ruth Stella Correa-Palacio, Expediente 50422-23-31-000-1369-01 (17.031). Disponible en: http://www.tesauro.com.co/ EJECUCIONpeta/CADUCIDAD\%202008.pdf

Colombia, Corte Constitucional, Sentencia C-417-93, 4 de octubre de 1993, magistrado ponente José Gregorio Hernández-Galindo. Disponible en: http://www.corteconstitucional.gov.co/relatoria/1993/c-417-93.htm

Colombia, Corte Constitucional, Sentencia C-214-94, 28 de abril de 1994, magistrado ponente Antonio BarreraCarbonell. Disponible en: http://www.corteconstitucional.gov.co/relatoria/1994/c-214-94.htm

Colombia, Corte Constitucional, Sentencia C-017-96, 23 de enero de 1996, magistrado ponente Alejandro MartínezCaballero. Disponible en: http://www.corteconstitucional.gov.co/relatoria/1996/c-017-96.htm

Colombia, Corte Constitucional, Sentencia C-102-96, 7 de marzo de 1996, magistrado ponente Alejandro MartínezCaballero. Disponible en: http://www.corteconstitucional.gov.co/relatoria/1996/c-102-96.htm

Colombia, Corte Constitucional, Sentencia C-280-96, 25 de junio de 1996, magistrado ponente Alejandro MartínezCaballero. Disponible en: http://www.corteconstitucional.gov.co/relatoria/1996/c-280-96.htm

Colombia, Corte Constitucional, Sentencia C-708-99, 22 de septiembre de 1999, magistrado ponente Álvaro TafurGalvis. Disponible en: http://www.corteconstitucional.gov.co/relatoria/1999/c-708-99.htm 
Colombia, Corte Constitucional, Sentencia C-827-01, 8 de agosto de 2001, magistrado ponente Álvaro Tafur-Galvis. Disponible en: http://www.corteconstitucional.gov.co/relatoria/2001/c-827-01.htm

Colombia, Corte Constitucional, Sentencia C-155-02, 5 de marzo de 2002, magistrada ponente Clara Inés VargasHernández. Disponible en: http://www.corteconstitucional.gov.co/relatoria/2002/c-155-02.htm

Colombia, Corte Constitucional, Sentencia C-948-02, 6 de noviembre de 2002, magistrado ponente Álvaro TafurGalvis. Disponible en: http://www.corteconstitucional.gov.co/relatoria/2002/c-948-02.htm

Colombia, Corte Constitucional, Sentencia C-977-02, 13 de noviembre de 2002, magistrado ponente Manuel José Cepeda-Espinosa. Disponible en: http://www.corteconstitucional.gov.co/relatoria/2002/c-977-02.htm

Colombia, Corte Constitucional, Sentencia C-1066-02, 3 de diciembre de 2002, magistrado ponente Jaime AraujoRentería. Disponible en: http://www.corteconstitucional.gov.co/relatoria/2002/c-1066-02.htm

Colombia, Corte Constitucional, Sentencia C-1076-02, 5 de diciembre de 2002, magistrada ponente Clara Inés Vargas-Hernández. Disponible en: http://www.corteconstitucional.gov.co/relatoria/2002/C-1076-02.htm

Colombia, Corte Constitucional, Sentencia C-037-03, 28 de enero de 2003, magistrado ponente Álvaro Tafur-Galvis. Disponible en: http://www.corteconstitucional.gov.co/relatoria/2003/C-037-03.htm

Colombia, Corte Constitucional, Sentencia C-530-03, 3 de julio de 2003, magistrado ponente Eduardo MontealegreLynett. Disponible en: http://www.corteconstitucional.gov.co/relatoria/2003/c-530-03.htm

Colombia, Corte Constitucional, Sentencia C-014-04, 20 de enero de 2004, magistrado ponente Jaime CórdobaTriviño. Disponible en: http://www.corteconstitucional.gov.co/relatoria/2004/c-014-04.htm

Colombia, Corte Constitucional, Sentencia C-590-05, 8 de junio de 2005, magistrado ponente Jaime CórdobaTriviño. Disponible en: http://www.corteconstitucional.gov.co/relatoria/2005/c-590-05.htm

Colombia, Corte Constitucional, Sentencia C-818-05, 9 de agosto de 2005, magistrado ponente Rodrigo Escobar-Gil. Disponible en: http://www.corteconstitucional.gov.co/relatoria/2005/c-818-05.htm

Colombia, Corte Constitucional, Sentencia C-213-07, 21 de marzo de 2007, magistrado ponente Humberto Antonio Sierra-Porto. Disponible en: http://www.corteconstitucional.gov.co/relatoria/2007/c-213-07.htm

Colombia, Corte Constitucional, Sentencia C-666-08, 2 de julio de 2008, magistrado ponente Mauricio GonzálezCuervo. Disponible en: http://www.corteconstitucional.gov.co/relatoria/2008/c-666-08.htm

Colombia, Corte Constitucional, Sentencia C-762-09, 29 de octubre de 2009, magistrado ponente Juan Carlos Henao-Pérez. Disponible en: http://www.corteconstitucional.gov.co/relatoria/2009/c-762-09.htm

Colombia, Corte Constitucional, Sentencia C-089-11, 16 de febrero de 2011, magistrado ponente Luis Ernesto Vargas-Silva. Disponible en: http://www.corteconstitucional.gov.co/relatoria/2011/c-089-11.htm

Colombia, Corte Constitucional, Sentencia C-306-12, 26 de abril de 2012, magistrado ponente Mauricio GonzálezCuervo. Disponible en: http://www.corteconstitucional.gov.co/relatoria/2012/c-306-12.htm

Colombia, Corte Constitucional, Sentencia C-315-12, 2 de mayo de 2012, magistrada ponente María Victoria CalleCorrea. Disponible en: http://www.corteconstitucional.gov.co/relatoria/2012/c-315-12.htm

Colombia, Corte Constitucional, Sentencia C-370-12, 16 de mayo de 2012, magistrado ponente Jorge Ignacio PreteltChaljub. Disponible en: http://www.corteconstitucional.gov.co/relatoria/2012/c-370-12.htm

Colombia, Corte Constitucional, Sentencia C-619-12, 8 de agosto de 2012, magistrado ponente Jorge Iván PalacioPalacio. Disponible en: http://www.corteconstitucional.gov.co/RELATORIA/2012/C-619-12.htm

Colombia, Corte Constitucional, Sentencia C-401-13, 3 de julio de 2013, magistrado ponente Mauricio GonzálezCuervo. Disponible en: http://www.corteconstitucional.gov.co/relatoria/2013/c-401-13.htm

Colombia, Corte Constitucional, Sentencia C-341-14, 4 de junio de 2014, magistrado ponente Mauricio GonzálezCuervo. Disponible en: http://www.corteconstitucional.gov.co/relatoria/2014/c-341-14.htm

Colombia, Corte Constitucional, Sentencia C-390-14, 26 de junio de 2014, magistrado ponente Alberto Rojas-Ríos. Disponible en: http://www.corteconstitucional.gov.co/relatoria/2014/c-390-14.htm

Colombia, Corte Constitucional, Sentencia C-792-14, 29 de octubre de 2014, magistrado ponente Luis Guillermo Guerrero-Pérez. Disponible en: http://www.corteconstitucional.gov.co/relatoria/2014/c-792-14.htm 
Colombia, Corte Constitucional, Sentencia C-794-14, 29 de octubre de 2014, magistrado ponente Mauricio González-Cuervo. Disponible en: http://www.corteconstitucional.gov.co/relatoria/2014/c-794-14.htm

Colombia, Corte Constitucional, Sentencia C-951-14, 4 de diciembre de 2014, magistrada ponente María Victoria Sáchica-Méndez. Disponible en: http://www.corteconstitucional.gov.co/relatoria/2014/c-951-14.htm

Colombia, Corte Constitucional, Sentencia C-532-15, 19 de agosto de 2015, magistrado ponente María Victoria Calle-Correa. Disponible en: http://www.corteconstitucional.gov.co/relatoria/2015/c-532-15.htm

Colombia, Corte Constitucional, Sentencia C-673-15, 28 de octubre de 2015, magistrado ponente Luis Ernesto Vargas-Silva. Disponible en: http://www.corteconstitucional.gov.co/relatoria/2015/c-673-15.htm

Colombia, Corte Constitucional, Sentencia C-699-15, 18 de noviembre de 2015, magistrado ponente Alberto RojasRíos. Disponible en: http://www.corteconstitucional.gov.co/relatoria/2015/c-699-15.htm

Colombia, Corte Constitucional, Sentencia C-721-15, 25 de noviembre de 2015, magistrado ponente Jorge Ignacio Pretelt-Chaljub. Disponible en: http://www.corteconstitucional.gov.co/relatoria/2015/c-721-15.htm

Colombia, Corte Constitucional, Sentencia C-135-16, 17 de marzo de 2016, magistrado ponente Luis Ernesto VargasSilva. Disponible en: http://www.corteconstitucional.gov.co/relatoria/2016/c-135-16.htm

Colombia, Corte Constitucional, Sentencia C-299-16, 8 de junio de 2016, magistrado ponente Luis Guillermo Guerrero-Pérez. Disponible en: http://www.corteconstitucional.gov.co/relatoria/2016/C-299-16.htm

Colombia, Corte Constitucional, Sentencia SU-712-13, 17 de octubre de 2013, magistrado ponente Jorge Iván Palacio-Palacio. Disponible en: http://www.corteconstitucional.gov.co/relatoria/2013/su712-13.htm

Colombia, Corte Constitucional, Sentencia SU-355-15, 11 de junio de 2015, magistrado ponente Mauricio GonzálezCuervo. Disponible en: http://www.corteconstitucional.gov.co/relatoria/2015/su355-15.htm

Colombia, Corte Constitucional, Sentencia SU-050-17, 2 de febrero de 2017, magistrado ponente Luis Ernesto Vargas-Silva. Disponible en: http://www.corteconstitucional.gov.co/relatoria/2017/su050-17.htm

Colombia, Corte Constitucional, Sentencia T-596-92, 10 de diciembre de 1992, magistrado ponente Ciro AngaritaBarón. Disponible en: http://www.corteconstitucional.gov.co/relatoria/1992/t-596-92.htm

Colombia, Corte Constitucional, Sentencia T-705-96, 9 de diciembre de 1996, magistrado ponente Eduardo Cifuentes-Muñoz. Disponible en: http://www.corteconstitucional.gov.co/relatoria/1996/t-705-96.htm

Colombia, Corte Constitucional, Sentencia T-120-98, 26 de marzo de 1998, magistrado ponente Fabio Morón-Díaz. Disponible en: http://www.corteconstitucional.gov.co/relatoria/1998/t-120-98.htm

Colombia, Corte Constitucional, Sentencia T-153-98, 28 de abril de 1998, magistrado ponente Eduardo CifuentesMuñoz. Disponible en: http://www.corteconstitucional.gov.co/relatoria/1998/t-153-98.htm

Colombia, Corte Constitucional, Sentencia T-702-01, 5 de julio de 2001, magistrado ponente Marco Gerardo Monroy-Cabra. Disponible en: http://www.corteconstitucional.gov.co/relatoria/2001/t-702-01.htm

Colombia, Corte Constitucional, Sentencia T-822-02, 4 de octubre de 2002, magistrado ponente Rodrigo EscobarGil. Disponible en: http://www.corteconstitucional.gov.co/relatoria/2002/t-822-02.htm

Colombia, Corte Constitucional, Sentencia T-133-06, 23 de febrero de 2006, magistrado ponente Humberto Antonio Sierra-Porto. Disponible en: http://www.corteconstitucional.gov.co/relatoria/2006/t-133-06.htm

Colombia, Corte Constitucional, Sentencia T-1034-06, 5 de diciembre de 2006, magistrado ponente Humberto Antonio Sierra-Porto. Disponible en: http://www.corteconstitucional.gov.co/relatoria/2006/t-1034-06.htm

Colombia, Corte Constitucional, Sentencia T-152-09, 12 de marzo de 2009, magistrada ponente Cristina PardoSchlesinger. Disponible en: http://www.corteconstitucional.gov.co/relatoria/2009/t-152-09.htm

Colombia, Corte Constitucional, Sentencia T-962-09, 18 de diciembre de 2009, magistrada ponente María Victoria Calle-Correa. Disponible en: http://www.corteconstitucional.gov.co/relatoria/2009/t-962-09.htm

Colombia, Corte Constitucional, Sentencia T-1012-10, 7 de diciembre de 2010, magistrada ponente María Victoria Calle-Correa. Disponible en: http://www.corteconstitucional.gov.co/relatoria/2010/t-1012-10.htm

Colombia, Corte Constitucional, Sentencia T-350-11, 5 de mayo de 2011, magistrada ponente María Victoria CalleCorrea. Disponible en: http://www.corteconstitucional.gov.co/relatoria/2011/t-350-11.htm 
Colombia, Corte Constitucional, Sentencia T-637-12, 16 de agosto de 2012, magistrado ponente Luis Ernesto VargasSilva. Disponible en: http://www.corteconstitucional.gov.co/relatoria/2012/t-637-12.htm

Colombia, Corte Constitucional, Sentencia T-120-14, 3 de marzo de 2014, magistrada ponente María Victoria CalleCorrea. Disponible en: http://www.corteconstitucional.gov.co/relatoria/2014/t-120-14.htm

Colombia, Corte Constitucional, Sentencia T-213-14, 1 de abril de 2014, magistrado ponente María Victoria CalleCorrea. Disponible en: http://www.corteconstitucional.gov.co/relatoria/2014/t-213-14.htm

Colombia, Corte Constitucional, Sentencia T-454-15, 21 de julio de 2015, magistrado ponente Miriam Ávila-Roldán. Disponible en: http://www.corteconstitucional.gov.co/relatoria/2015/t-454-15.htm

Colombia, Corte Constitucional, Sentencia T-518-14, 17 de julio de 2014, magistrado ponente Jorge Ignacio PreteltChaljub. Disponible en: http://www.corteconstitucional.gov.co/relatoria/2014/t-518-14.htm

Colombia, Corte Constitucional, Sentencia T-212-16, 27 de abril de 2016, magistrado ponente Gabriel Eduardo Mendoza-Martelo. Disponible en: http://www.corteconstitucional.gov.co/relatoria/2016/t-212-16.htm

Colombia, Corte Constitucional, Sentencia T-265-16, 23 de mayo de 2016, magistrado ponente Jorge Iván PalacioPalacio. Disponible en: http://www.corteconstitucional.gov.co/relatoria/2016/t-265-16.htm

Colombia, Corte Constitucional, Sentencia T-009-17, 20 de enero de 2017, magistrado ponente Alberto Rojas-Ríos. Disponible en: http://www.corteconstitucional.gov.co/relatoria/2017/t-009-17.htm

Colombia, Corte Constitucional, Sentencia T-119-17, 27 de febrero de 2017, magistrado ponente Luis Ernesto VargasSilva. Disponible en: http://www.corteconstitucional.gov.co/relatoria/2017/t-119-17.htm

Colombia, Corte Suprema de Justicia, Sala de Casación Penal, Sentencia de Justicia, Sentencia de 4 de marzo de 2015, magistrado ponente Eugenio Fernández-Carlier, SP 2192-2015, Radicación 38635. Disponible en: http://www .cortesuprema.gov.co/corte/wp-content/uploads/relatorias/pe/blabr2015/SP2192-2015(38635).doc

Colombia, Corte Suprema de Justicia, Sala de Casación Penal, Sentencia de Justicia, Sentencia de 2 de diciembre de 2015, magistrado ponente José Luis Barceló-Camacho, SP 16558-2015, Radicación 44840. Disponible en: http ://www.cortesuprema.gov.co/corte/wp-content/uploads/2016/01/SP16558-201544840.pdf

\section{Notas}

1 Colombia, Corte Constitucional, Sentencia C-214-94, 28 de abril de 1994, magistrado ponente Antonio BarreraCarbonell. Colombia, Corte Constitucional, Sentencia C-948-02, 6 de noviembre de 2002, magistrado ponente Álvaro Tafur- Galvis. Colombia, Corte Constitucional, Sentencia C-530-03, 3 de julio de 2003, magistrado ponente Eduardo Montealegre-Lynett. Colombia, Corte Constitucional, Sentencia C-818-05, 9 de agosto de 2005, magistrado ponente Rodrigo Escobar-Gil. Colombia, Corte Constitucional, Sentencia C-666-08, 2 de julio de 2008, magistrado ponente Mauricio González-Cuervo.

2 Colombia, Corte Constitucional, Sentencia C-721-15, 25 de noviembre de 2015, magistrado ponente Jorge Ignacio Pretelt-Chaljub.

3 RAMÓN PARADA-VÁZQUEZ, Derecho administrativo II. Organización y empleo público, 579 (Marcial Pons, Madrid, 2008).

4 Colombia, Corte Constitucional, Sentencia C-827-01, 8 de agosto de 2001, magistrado ponente Álvaro Tafur-Galvis.

5 MARÍA CALVO-CHARRO, Sanciones medioambientales, 87 (Marcial Pons, Madrid, 1999). FRANCISCO SANZGANDASEGUI, La potestad sancionatoria de la Administración: la Constitución española y el Tribunal Constitucional, 84 (Editoriales de Derecho Reunidas, Madrid, 1985).

6 Entendiendo que este concepto está integrado por elementos como la confianza y la lealtad. Así lo aborda detalladamente MORELL-OCAÑA. LUIS MORELL-OCAÑA, La lealtad y otros componentes de la ética institucional de la Administración, 114 Revista Española de Derecho Administrativo, 165-194 (2002).

7 Colombia, Corte Constitucional, Sentencia C-708-99, 22 de septiembre de 1999, magistrado ponente Álvaro TafurGalvis.

8 Sobre este punto hay que recordar que: "la consideración de la voluntad de los particulares como habilitadora de potestades administrativas había sido ya formulada por los tratadistas de la evaluación conceptual sufrida por una de las instituciones claves del Derecho Administrativo: la autorización”. JOSÉ MARÍA MICHAVILA-NÚNEZ, Relación especial de sujeción, en el sector crediticio y estado de derecho, 54 Revista Española de Derecho Administrativo, 243-268, 252 (1987). Al respecto, GALLEGO-ANABITARTE pone en entredicho la supuesta voluntariedad, al sostener: "Por 
otra parte, naturalmente, que nadie tiene obligación de ser funcionario; sin embargo, muchas veces no es esto sino una obligada consecuencia de las condiciones sociales”. ALFREDO GALLEGO-ANABITARTE, Las relaciones especiales de sujeción y el principio de la legalidad de la Administración, 34 Revista de Administración Pública, 11-51, 41 (1961).

9 ÁNGELES DE PALMA DEL TESO, Comentarios al titulo IX de la potestad sancionadora de la ley 30/1992, en Administración Pública y Procedimiento Administrativo: comentarios a la Ley 30/1992, de 26 de noviembre, 467-506, 473 (JOAQUÍN TORNOS-MAS, coord., Bosch, Barcelona, 1994).

10 MARÍA LOURDES RAMÍREZ-TORRADO \& HERNANDO V. ANÍBAL-BENDEK, Sanción administrativa en Colombia, 131 Vniversitas, 107-148 (2015).

11 Colombia, Corte Constitucional, Sentencia C-037-03, 28 de enero de 2003, magistrado ponente Álvaro Tafur-Galvis.

12 Colombia, Ley 734 de 2002, por la cual se expide el Código Disciplinario Único, CDU, 44.708 Diario Oficial, 13 de febrero de 2002, artículo 53.

13 Colombia, Constitución Política, 116 Gaceta Constitucional, 20 de julio de 1991, artículo 29.

14 Colombia, Corte Constitucional, Sentencia C-089-11, 16 de febrero de 2011, magistrado ponente Luis Ernesto VargasSilva.

15 Para este tema: WILSON YESID SUÁREZ-MANRIQUE, La constitucionalización del derecho en el ordenamiento jurídico colombiano, 129 Vniversitas, 317-351 (2014). LUISA FERNANDA GARCÍA-LÓPEZ, El juez y el precedente: hacia una reinterpretación de la separación de poderes, 128 Vniversitas, 79-120 (2014).

16 BERNARDO CARVAJAL-SÁNCHEZ, Alcance y limitaciones del debido proceso en el procedimiento administrativo, 4 Revista Digital de Derecho Administrativo, 7-21 (2010).

17 JAIME OSSA-ARBELÁEZ, Derecho administrativo sancionador. Una aproximación dogmática, 447 (Legis, Bogotá, 2000).

18 NELSON HERNÁNDEZ-MEZA, Concepto del principio de legalidad en el derecho disciplinario según la doctrina colombiana. Una creación a partir de la doctrina y la jurisprudencia española, en Ensayos sobre derecho disciplinario, 55-102 (Ediciones Nueva Jurídica, Colegio de Abogados en Derecho Disciplinario, Bogotá, 2013).

19 Colombia, Corte Constitucional, Sentencia C-619-12, 8 de agosto de 2012, magistrado ponente Jorge Iván PalacioPalacio. Colombia, Corte Constitucional, Sentencia C-135-16, 17 de marzo de 2016, magistrado ponente Luis Ernesto Vargas-Silva.

20 Colombia, Corte Constitucional, Sentencia C-699-15, 18 de noviembre de 2015, magistrado ponente Alberto RojasRíos.

21 Entre otras providencias, pueden verse: Colombia, Corte Constitucional, Sentencia C-532-15, 19 de agosto de 2015, magistrado ponente María Victoria Calle-Correa. Colombia, Corte Constitucional, Sentencia C-401-13, 3 de julio de 2013, magistrado ponente Mauricio González-Cuervo. Colombia, Corte Constitucional, Sentencia C-370-12, 16 de mayo de 2012, magistrado ponente Jorge Ignacio Pretelt-Chaljub.

22 Colombia, Consejo de Estado, Sala de lo Contencioso Administrativo, Sección Segunda, Subsección A, Sentencia de 26 de septiembre de 2012, consejero ponente Gustavo Eduardo Gómez-Aranguren, Radicación 11001-03-25-000-201000127-00(0977-10).

23 LEONARDO GARCÍA-JARAMILLO, Buenos tiempos para el neoconstitucionalismo (sobre la aparición del examen de proporcionalidad en el derecho constitucional), 120 Vniversitas, 317-332 (2010).

24 Colombia, Corte Constitucional, Sentencia C-721-15, 25 de noviembre de 2015, magistrado ponente Jorge Ignacio Pretelt-Chaljub. Colombia, Corte Constitucional, Sentencia C-951-14, 4 de diciembre de 2014, magistrada ponente María Victoria Sáchica-Méndez.

25 Colombia, Consejo de Estado, Sala de lo Contencioso Administrativo, Sección Segunda, Subsección B, Sentencia de 4 de febrero de 2016, consejera ponente Sandra Lisset Ibarra-Vélez, Radicación 11001-032-5000-2013-01790-00(4752-13).

26 Colombia, Consejo de Estado, Sala de lo Contencioso Administrativo, Sección Segunda, Subsección A, Sentencia de 19 de febrero de 2015, Consejero ponente Gustavo Eduardo Gómez-Aranguren, Radicación 11001-03-25-000-2011-00606-00 (2319-11).

27 Colombia, Consejo de Estado, Sala de lo Contencioso Administrativo, Sección Segunda, Subsección A, Sentencia de 2 de mayo de 2013, consejero ponente Alfonso Vargas-Rincón, Radicación 25000232500020040583501 (07312008).

28 JAIME MEJÍA-OSSMAN, Régimen disciplinario, 252-259 (Ediciones Doctrina y Ley, Bogotá, 2007).

29 Colombia, Corte Constitucional, Sentencia T-1012-10, 7 de diciembre de 2010, magistrada ponente María Victoria Calle-Correa.

30 Colombia, Corte Constitucional, Sentencia C-977-02, 13 de noviembre de 2002, magistrado ponente Manuel José Cepeda-Espinosa.

31 Colombia, Corte Constitucional, Sentencia C-037-03, 28 de enero de 2003, magistrado ponente Álvaro Tafur-Galvis.

32 Ley 734 de 2002, artículo 160.

33 Colombia, Corte Constitucional, Sentencia C-315-12, 2 de mayo de 2012, magistrada ponente María Victoria CalleCorrea. 
34 Colombia, Consejo de Estado, Sala de lo Contencioso Administrativo, Sección Segunda, Subsección B, Sentencia de 18 de febrero de 2016, consejera ponente Sandra Lisset Ibarra-Vélez, Radicación 810012333000201400025-01(1582-2015).

35 Colombia, Consejo de Estado, Sala de lo Contencioso Administrativo, Sección Segunda, Subsección A, Sentencia de 20 de octubre de 2014, consejero ponente Alfonso Vargas-Rincón, Radicación 11001-03-25-000-2012-00172-00(0748-12).

36 Colombia, Consejo de Estado, Sala de lo Contencioso Administrativo, Sección Segunda, Subsección B, Sentencia de 27 de noviembre de 2014, consejera ponente Sandra Lisset Ibarra-Vélez, Radicación 11001-03-25-000-2010-00196-00 (1486-10).

37 Colombia, Consejo de Estado, Sala de lo Contencioso Administrativo, Sección Segunda, Subsección A, Sentencia de 23 de septiembre de 2015, consejero ponente Jorge Octavio Ramírez-Ramírez, Radicación 11001-03-25-000-201000162-00(1200-10).

38 Colombia, Consejo de Estado, Sala de lo Contencioso Administrativo, Sección Segunda, Subsección A, Sentencia de 4 de marzo de 2016, consejero ponente Gabriel Valbuena-Hernández, Radicación 11001-03-25-000-2012-0009800(0438-12).

39 Colombia, Consejo de Estado, Sala de lo Contencioso Administrativo, Sección Segunda, Subsección B, Sentencia de 4 de febrero de 2016, consejera ponente Sandra Lisset Ibarra-Vélez, Radicación 1 1001-03-25-000-2012-00146-00(0627-12).

40 Colombia, Corte Suprema de Justicia, Sala de Casación Penal, Sentencia de Justicia, Sentencia de 4 de marzo de 2015, magistrado ponente Eugenio Fernández-Carlier, SP 2192-2015, Radicación 38635.

41 ESIQUIO MANUEL SÁNCHEZ-HERRERA, Dogmática practicable del derecho disciplinario, preguntas y respuestas, 76-82 (Ediciones Nueva Jurídica, Bogotá, 2007).

42 Colombia, Consejo de Estado, Sala de lo Contencioso Administrativo, Sección Segunda, Subsección A, Sentencia de 4 de marzo de 2016, consejero ponente Gabriel Valbuena-Hernández, Radicación 11001-03-25-000-2012-00098-00(0438-12).

43 Para que el error invencible opere, el Consejo de Estado ha señalado que el disciplinado tiene que tener la "creencia plena y sincera de que actuaba ajustado al ordenamiento jurídico, y adicionalmente, que el error de apreciación no era humanamente superable dadas las condiciones personales del procesado y las circunstancias en que este se realizó". Colombia, Consejo de Estado, Sala de lo Contencioso Administrativo, Sección Primera, Sentencia de 27 de noviembre de 2015, consejero ponente Roberto Serrato-Valdés, Radicación 6800-1233-3000- 2015-00324-01(PI).

44 Colombia, Consejo de Estado, Sala de lo Contencioso Administrativo, Sección Segunda, Subsección B, Sentencia de 16 de abril de 2015, consejera ponente Sandra Lisset Ibarra-Vélez, Radicación 11001-03-25-000-2012-00352-00(135312).

45 Colombia, Consejo de Estado, Sala de lo Contencioso Administrativo, Sección Segunda, Sentencia de 2 de agosto de 2012, consejera ponente Martha Teresa Briceño de Valencia, Expediente 2004-00030 (17939). Colombia, Consejo de Estado, Sala de lo Contencioso Administrativo, Sección Primera, Sentencia de 23 de enero de 2014, consejera ponente María Claudia Rojas-Lasso, Radicación 25000-23-24-000-2002-00176-01.

46 Colombia, Corte Constitucional, Sentencia T-152-09, 12 de marzo de 2009, magistrada ponente Cristina PardoSchlesinger.

47 Colombia, Consejo de Estado, Sala de lo Contencioso Administrativo, Sección Segunda, Subsección B, Sentencia de 11 de julio de 2013, consejero ponente Gerardo Arenas-Monsalve, Radicación 52001-23-31-000-2004-00188-02(198209).

48 Colombia, Corte Suprema de Justicia, Sala de Casación Penal, Sentencia de Justicia, Sentencia de 2 de diciembre de 2015, magistrado ponente José Luis Barceló-Camacho, SP 16558-2015, Radicación 44840 (aprobado Acta No. 428).

49 Colombia, Corte Constitucional, Sentencia C-1076-02, 5 de diciembre de 2002, magistrada ponente Clara Inés VargasHernández.

50 El principio de independencia en unas de sus acepciones contempla el principio de imparcialidad, así: "consiguientemente, los significados de la independencia; y el segundo es más complejo y encuentra su enlace con la separación de poderes”. MARÍA ISABEL GARRIDO-GÓMEZ, La función de los jueces: contexto, actividades e instrumentos, 174 (Aranzadi, Navarra, 2014). A lo que PERFECTO ANDRÉS IBÁÑEZ agrega: "Estrechamente interimplicados, independencia e imparcialidad son, pues términos conceptualmente susceptibles de deslinde, mediante análisis. (...) Por tanto, la independencia guarda relación con la posición de la magistratura en el marco estatal y la del juez en el contexto orgánico. La imparcialidad tiene en la independencia un presupuesto o condición de posibilidad; y su espacio propio de actuación en el enjuiciamiento". PERFECTO ANDRÉS IBÁÑEZ, Imparcialidad judicial e independencia judicial, en La imparcialidad judicial, 41-72, 53 (CARLOS GÓMEZ-MARTÍNEZ, dir., Consejo General del Poder Judicial, Madrid, 2008).

51 Colombia, Corte Constitucional, Sentencia C-794-14, 29 de octubre de 2014, magistrado ponente Mauricio GonzálezCuervo. 
52 Esta prohibición se encuentra establecida en forma expresa en el artículo 127 constitucional.

53 Colombia, Consejo de Estado, Sala de lo Contencioso Administrativo, Sección Segunda, Subsección A, Sentencia de 7 de noviembre de 2013, consejero ponente Gustavo Eduardo Gómez-Aranguren, Radicación 11001-03-25-000-2011-00084-00(0256-11) 6.

54 La actividad del juzgador no es, ni puede ser un ejercicio matemático, "los factores que inciden en el mundo de los valores de una sociedad, en su sensibilidad, es indudable que tienen que influir en el que decide, pero se quiere que lo hagan de manera neutra. Las pasiones de los hombres entrarán en juego inevitablemente, pero a condición de que sean tenidas en cuenta por un observador desapasionado, que las valores como un criterio más, de acuerdo con la importancia que la realidad social les otorgue en un momento determinado”. PLÁCIDO FERNÁNDEZ-VIAGAS BARTOLOMÉ, El juez imparcial, 2 (Comares, Granada, 1997).

55 Colombia, Corte Constitucional, Sentencia T-1034-06, 5 de diciembre de 2006, magistrado ponente Humberto Antonio Sierra-Porto.

56 Colombia, Consejo de Estado, Sala de lo Contencioso Administrativo, Sección Segunda, Subsección B, Sentencia de 16 de marzo de 2015, consejero ponente Sandra Lisset Ibarra-Vélez, Radicación 11001-03-25-000-2011-00326-00(123311).

57 Colombia, Corte Constitucional, Sentencia C-762-09, 29 de octubre de 2009, magistrado ponente Juan Carlos HenaoPérez.

58 RAFAEL JIMÉNEZ-ASENSIO, Imparcialidad judicial y derecho al juez imparcial, 199-202 (Cizur Menor, Aranzadi, Navarra, 2002).

59 FRANCISCO GARCÍA-GÓMEZ DE MERCADO, Sanciones administrativas. Garantías, derechos y recursos del presunto responsable, 103 (Comares, Granada, 2007).

60 Con quienes diferencian imparcialidad e independencia de la siguiente manera: "el deber de independencia trata de controlar los móviles del juez frente a influencias extrañas al Derecho provenientes desde fuera del proceso jurisdiccional, es decir, provenientes del sistema social en general. (...) el deber de imparcialidad, por el contrario, trata de controlar los móviles del juez frente a influencias extrañas al Derecho provenientes desde dentro del proceso jurisdiccional". JOSEP AGUILÓ-REGLA, Imparcialidady aplicación de la ley, en La imparcialidad judicial, 139-166, 145 (CARLOS GÓMEZ-MARTÍNEZ, dir., Consejo General del Poder Judicial, Madrid, 2008).

61 Frente a la independencia judicial, FRANCISCO SOSA-WAGNER expresa: "incluye, de un lado, ingredientes sustantivos como son el nombramiento a una carrera — traslados voluntarios, ascensos, jubilación, etc.— a medida que se acumulan sobre él años, canas, lecturas de textos abstrusos y amarguras; de otro, su exclusiva vinculación a la ley y, en su caso, a la jurisprudencia de los tribunales, así como su carácter ajeno a los intereses de las partes sometidas a sus decisiones [imparcialidad]. Dicho de otro modo: el ingreso en la profesión judicial, el ejercicio en condiciones seguras de su trabajo, libre de intereses y de vinculaciones jerárquicas (ningún superior puede transmitirle instrucciones)”. FRANCISCO SOSA-WAGNER, La independencia del juez: ¿una fábula? Un relato escrito para personas curiosas y legas, 28-29 (La Esfera de los Libros, Madrid, 2016). De este principio se desprenden tres vertientes diferentes: "1. Independencia institucional del poder judicial: no solo como conjunto orgánico, sino como institución dotada de relevante papel de poder político en la articulación estatal. 2. Independencia organizativa: esto es, del conjunto organizado que forman los jueces y magistrados, conseguida paso a paso, mediante fórmulas de carácter orgánico primero, que tratan de separar a los jueces de la influencia de otros poderes. 3. Independencia orgánica del titular del órgano judicial”. PIEDAD GONZÁLEZ-GRANDA, Independencia del juez y control de su actividad, 22 (Tirant lo Blanch, Valencia, 1993).

62 Colombia, Corte Constitucional, Sentencia C-673-15, 28 de octubre de 2015, magistrado ponente Luis Ernesto VargasSilva.

63 Colombia, Consejo de Estado, Sala de lo Contencioso Administrativo, Sección Segunda, Subsección B, Sentencia de 27 de noviembre de 2014, consejera ponente Sandra Lisset Ibarra-Vélez, Radicación 11001-03-25-000-2010-00196-00 (1486-10).

64 JOSÉ GARBERÍ-LLOBREGAT, La aplicación de los derechos y garantías constitucionales a la potestad y al procedimiento administrativo sancionador, 121 (Trivium, Madrid, 1989).

65 Colombia, Corte Constitucional, Sentencia T-822-02, 4 de octubre de 2002, magistrado ponente Rodrigo Escobar-Gil.

66 Colombia, Consejo de Estado, Sala de Servicio y Consulta Civil, Concepto de 30 de octubre de 2013, consejero ponente William Zambrano-Cetina, Radicación: 2163. Numero Único: 11001030600020130040000 . En este concepto se respondió la consulta presentada por el Ministerio del Trabajo en este sentido.

67 Entre muchas otras: Corte Interamericana de Derechos Humanos, CorteIDH, Caso Ricardo Canese vs. Paraguay, Serie C-111, Sentencia del 31 de agosto de 2004, fondo, reparaciones y costas. Corte Interamericana de Derechos Humanos, CorteIDH, Caso 19 comerciantes vs. Colombia, Serie C-109, Sentencia del 5 de julio de 2004, fondo, reparaciones y costas.

68 Colombia, Corte Constitucional, Sentencia T-518-14, 17 de julio de 2014, magistrado ponente Jorge Ignacio PreteltChaljub. 
69 Sobre el particular, Convención Americana sobre Derechos Humanos, artículo 8. Pacto Internacional de Derechos Civiles y Políticos, artículo 14.

70 Colombia, Corte Constitucional, Sentencia C-390-14, 26 de junio de 2014, magistrado ponente Alberto Rojas-Ríos.

71 Colombia, Consejo de Estado, Sala de lo Contencioso Administrativo, Sección Segunda, Subsección B, Sentencia de 30 de julio de 2015, consejera ponente Sandra Lisset Ibarra-Vélez, Radicación 11001-03-25-000-2010-00142-00 (06092012).

72 Colombia, Corte Constitucional, Sentencia C-792-14, 29 de octubre de 2014, magistrado ponente Luis Guillermo Guerrero-Pérez.

73 Colombia, Corte Constitucional, Sentencia C-155-02, 5 de marzo de 2002, magistrada ponente Clara Inés VargasHernández.

74 CARLOS ARTURO GÓMEZ-PAVAJEAU, El derecho disciplinario como disciplina jurídica autónoma, 95 Revista Derecho Penal y Criminología, 51-68 (2012). DAVID ROA-SALGUERO, La jurisprudencia del Consejo de Estado y sus recientes aportes al derecho disciplinario, 94 Revista Derecho Penal y Criminología, 97-126 (2012).

75 Colombia, Corte Constitucional, Sentencia C-017-96, 23 de enero de 1996, magistrado ponente Alejandro MartínezCaballero. Colombia, Corte Constitucional, Sentencia C-213-07, 21 de marzo de 2007, magistrado ponente Humberto Antonio Sierra-Porto.

76 Colombia, Corte Constitucional, Sentencia C-280-96, 25 de junio de 1996, magistrado ponente Alejandro MartínezCaballero. Colombia, Corte Constitucional, Sentencia C-102-96, 7 de marzo de 1996, magistrado ponente Alejandro Martínez-Caballero. Colombia, Corte Constitucional, Sentencia C-401- 13, 3 de julio de 2013, magistrado ponente Mauricio González-Cuervo.

77 Colombia, Corte Constitucional, Sentencia C-792-14, 29 de octubre de 2014, magistrado ponente Luis Guillermo Guerrero-Pérez.

78 Ley 734 de 2002, artículo 205.

79 Convención Americana sobre Derechos Humanos, artículo 8, numeral 2, literal h.

80 Colombia, Corte Constitucional, Sentencia T-962-09, 18 de diciembre de 2009, magistrada ponente María Victoria Calle-Correa. Colombia, Corte Constitucional, Sentencia T-637-12, 16 de agosto de 2012, magistrado ponente Luis Ernesto Vargas-Silva. Colombia, Corte Constitucional, Sentencia T-213-14, 1 de abril de 2014, magistrado ponente María Victoria Calle-Correa.

81 Colombia, Corte Constitucional, Sentencia C-014-04, 20 de enero de 2004, magistrado ponente Jaime CórdobaTriviño. Colombia, Corte Constitucional, Sentencia C-306-12, 26 de abril de 2012, magistrado ponente Mauricio González- Cuervo.

82 LEONARDO GARCÍA-JARAMILLO, De la “constitucionalización” a la "convencionalización" del ordenamiento jurídico. La contribución del ius constitutionale commune, 36 Revista Derecho del Estado, 131-166 (2016).

83 Colombia, Consejo de Estado, Sala de lo Contencioso Administrativo, Sección Segunda, Auto de 13 de mayo de 2014, consejero ponente Gerardo Arenas- Monsalve, Radicación 11001-03-25-000-2014-00360-00(1131-14).

84 Colombia, Consejo de Estado, Sala de lo Contencioso Administrativo, Sección Segunda, Sentencia de 11 de julio de 2013, consejero ponente Gustavo Gómez- Aranguren, Radicación 2011-0122.

85 MANUEL FERNANDO QUINCHE-RAMÍREZ sostiene: "los jueces y órganos vinculados a la administración de justicia en todos los niveles están en la obligación de ejercer ex officio un control de convencionalidad entre las normas internas y la Convención Americana”. MANUEL FERNANDO QUINCHE-RAMÍREZ, El control de convencionalidad, 151 (Temis, Bogotá, 2014).

86 Colombia, Consejo de Estado, Sala de lo Contencioso Administrativo, Sección Segunda, Subsección A, Sentencia de 26 de marzo de 2014, consejero ponente Gustavo Eduardo Gómez-Aranguren, Radicación 11001-03-25-000-2013-0011700(0263-13).

87 Colombia, Consejo de Estado, Sala de lo Contencioso Administrativo, Sección Segunda, Subsección A, Sentencia de 10 de marzo de 2016, consejero ponente Gabriel Valbuena-Hernández, Radicación 11001-03-25-000-2011-0061500(2368-11).

88 Colombia, Corte Constitucional, Sentencia C-590-05, 8 de junio de 2005, magistrado ponente Jaime Córdoba-Triviño.

89 Colombia, Corte Constitucional, Sentencia T-009-17, 20 de enero de 2017, magistrado ponente Alberto Rojas-Ríos.

90 Colombia, Corte Constitucional, Sentencia T-454-15, 21 de julio de 2015, magistrado ponente Miriam Ávila-Roldán.

91 Colombia, Corte Constitucional, Sentencia SU-050-17, 2 de febrero de 2017, magistrado ponente Luis Ernesto VargasSilva.

92 Colombia, Corte Constitucional, Sentencia T-350-11, 5 de mayo de 2011, magistrada ponente María Victoria CalleCorrea.

93 Colombia, Corte Constitucional, Sentencia SU-712-13, 17 de octubre de 2013, magistrado ponente Jorge Iván PalacioPalacio. 
94 Colombia, Corte Constitucional, Sentencia SU-355-15, 11 de junio de 2015, magistrado ponente Mauricio GonzálezCuervo.

95 Colombia, Consejo de Estado, Sala de lo Contencioso Administrativo, Sección Segunda, Auto de 13 de mayo de 2014, consejero ponente Gerardo Arenas-Monsalve, Radicación 11001-03-25-000-2014-00360-00(1131-14).

96 Colombia, Corte Constitucional, Sentencia T-119-17, 27 de febrero de 2017, magistrado ponente Luis Ernesto VargasSilva.

97 Colombia, Corte Constitucional, Sentencia T-350-11, 5 de mayo de 2011, magistrada ponente María Victoria CalleCorrea.

98 Colombia, Corte Constitucional, Sentencia T-265-16, 23 de mayo de 2016, magistrado ponente Jorge Iván PalacioPalacio.

99 Colombia, Corte Constitucional, Sentencia C-1066-02, 3 de diciembre de 2002, magistrado ponente Jaime AraujoRentería.

100 Colombia, Corte Constitucional, Sentencia C-1066-02, 3 de diciembre de 2002, magistrado ponente Jaime AraujoRentería.

101 Colombia, Corte Constitucional, Sentencia T-212-16, 27 de abril de 2016, magistrado ponente Gabriel Eduardo Mendoza-Martelo.

102 Colombia, Corte Constitucional, Sentencia T-120-98, 26 de marzo de 1998, magistrado ponente Fabio Morón-Díaz.

103 Colombia, Consejo de Estado, Sala de lo Contencioso Administrativo, Sección Segunda, Subsección A, Sentencia de 12 de mayo de 2014, consejero ponente Alfonso Vargas-Rincón, Radicación 08001-23-31-000-2000-02331-01(0360-09).

104 Colombia, Consejo de Estado, Sala de lo Contencioso Administrativo, Sección Segunda, Subsección A, Sentencia de 19 de agosto de 2010, consejero ponente Alfonso Vargas-Rincón, Radicación 70001-23-31-000-2000-00132-01(4394-03).

105 Colombia, Consejo de Estado, Sala de lo Contencioso Administrativo, Sección Segunda, Subsección A, Sentencia de 23 de septiembre de 2015, consejero ponente Jorge Octavio Ramírez-Ramírez, Radicación 11001-03-25-000-201000162-00(1200-10).

106 Colombia, Consejo de Estado, Sala de lo Contencioso Administrativo, Sección Segunda, Subsección A, Sentencia de 7 de noviembre de 2013, consejero ponente Gustavo Eduardo Gómez-Aranguren, Radicación 11001-03-25-000-2011-00084-00(0256-11).

107 Colombia, Consejo de Estado, Sala de lo Contencioso Administrativo, Sección Segunda, Subsección A, Sentencia de 19 de mayo de 2016, consejero ponente Gabriel Valbuena-Hernández, Radicación 11001-03-25-000-2010-0014200(1064-10).

108 Colombia, Consejo de Estado, Sección Tercera, Sentencia de 20 de noviembre de 2008, consejera ponente Ruth Stella Correa-Palacio, Expediente 50422-23-31-000-1369-01 (17.031).

109 Colombia, Corte Constitucional, Sentencia T-120-14, 3 de marzo de 2014, magistrada ponente María Victoria CalleCorrea.

* Artículo de investigación.

\section{Licencia Creative Commons CC BY 4.0}

Para citar este articulo / To cite this article: RAMÍREZ-TORRADO, MARÍA LOURDES \& HERNÁNDEZ-MEZA, NELSON, Los contornos flexibles del principio del debido proceso en las sanciones disciplinarias, 138 Vniversitas (2019). https://doi.org/10.11144/Javeriana.vj138.cfpd 